\title{
A cooperação em uma federação heterogênea: o regime de colaboração na educação em seis estados brasileiros
}

\author{
CATARINA IANNI SEGATTO \\ Fundação Getúlio Vargas, São Paulo, SP, Brasil \\ FERNANDO LUIZ ABRUCIO \\ Fundação Getúlio Vargas, São Paulo, SP, Brasil
}

RESUMO

Este artigo analisa a atuação dos governos estaduais no processo de coordenação federativa em municípios no campo da educação. A literatura reforça o crescente papel coordenador do governo federal nas políticas sociais, incluindo na área educacional, porém há poucos estudos sobre o papel dos estados. Para isso, foram analisadas a cooperação entre estados e municípios em seis estados: Acre, Ceará, Mato Grosso do Sul, Minas Gerais, Pará e São Paulo. O trabalho foi realizado com base em análise documental e entrevistas semiestruturadas com gestores das secretarias estaduais de educação, das secretarias municipais de educação e do Ministério da Educação e com atores de organizações não governamentais. A pesquisa empírica mostrou que há diversos modelos de cooperação entre estados e municípios, existindo, em apenas um estado, um modelo de coordenação estadual caracterizado por uma lógica mais permanente, institucionalizada e sistêmica de atuação.

PALAVRAS-CHAVE

cooperação; educação; relações intergovernamentais. 


\section{COOPERATION IN A HETEROGENEOUS FEDERATION: THE COLABORATION SYSTEM OF EDUCATION IN SIX BRAZILIAN STATES}

\section{ABSTRACT}

This article examines the role of state governments in federal coordination with municipalities in education policy. The literature reinforces the importance of the Federal Government as a coordinator of social policy, including education, but there are few studies about the existence and nature of states coordination on Brazilian educational public policy. The empirical analysis is based on a comparison of six states: Acre, Ceará, Mato Grosso do Sul, Minas Gerais, Pará and São Paulo. The methodology includes analysis of documents and qualitative interviews with managers of state and municipal education departments, managers of the Ministry of Education and administrators of non-governmental social organizations. Empirical research has shown that there are different models of cooperation between states and municipalities and there is only one case with a model of state coordination, which is characterized by a permanent, institutionalized and systemic logic of action.

\section{KEYWORDS}

cooperation; education; intergovernmental relations.

\section{LA COOPERACIÓN EN UNA FEDERACIÓN HETEROGÉNEA: EL SISTEMA DE COLABORACIÓN EN LA EDUCACIÓN EN SEIS ESTADOS BRASILEÑOS}

\section{RESUMEN}

Este artículo examina el rol de los gobiernos estaduales en el proceso de coordinación federativa en municipios en el área de la educación. La literatura refuerza el creciente rol coordinador del gobierno federal en las políticas sociales, incluso en el área educativa, pero hay pocos estudios sobre el rol de los estados. Con tal objeto se analizó la cooperación entre estados y municipios en seis estados: Acre, Ceará, Mato Grosso do Sul, Minas Gerais, Pará y São Paulo. El estudio se realizó por medio de análisis documental y entrevistas mixtas con gestores de las secretarias estaduales de educación, secretarias municipales de educación, Ministerio de Educación, y actores de las organizaciones no gubernamentales. La investigación empírica ha demostrado que hay diversos modelos de cooperación entre estados y municipios, existiendo solamente en un estado un modelo de coordinación estadual, caracterizado por una lógica más permanente, institucionalizada y sistémica de actuación.

\section{PALABRAS CLAVE}

colaboración; educación; relaciones intergubernamentales. 


\section{INTRODUÇÃO}

Com a redemocratização e a Constituição Federal de 1988, as políticas sociais passaram a se orientar por três objetivos: a expansão universalizada do acesso aos serviços públicos, a descentralização, particularmente da implementação das políticas, e a criação de sistemas de políticas públicas, cujo modelo de referência é o Sistema Único de Saúde (SUS), que busca articular e coordenar a ação dos entes federados. Essa última tarefa tem sido a mais complexa de todas, envolvendo intrincadas negociações entre a União, estados e municípios, com diferentes graus de sucesso entre os setores (Abrucio; Franzese; Sano, 2010).

A política de educação também passou por essas mudanças, e nela o tema da coordenação federativa, embora presente na Constituição por meio do conceito de regime de colaboração, teve um impulso maior somente a partir de 1995 . Nesse período, a atuação do governo federal como coordenador da política foi fortalecida, processo que teve continuidade e foi ampliado no Governo Lula. Para constituir esse novo padrão coordenador, foram criados mecanismos de redistribuição de recursos, indução financeira para adoção de determinados programas, diretrizes e regulamentação e de sistemas de avaliação e informação nacionais.

Essas modificações tornaram mais complexas as relações intergovernamentais na educação, com maior ativismo da União e aumento da participação dos municípios na provisão da política. Porém, os estados continuaram com um papel central, seja pelo tamanho de sua rede de ensino (que detém o maior número de alunos no segundo ciclo do ensino fundamental), seja por sua maior capacidade de articulação com os governos locais. Observa-se que há uma grande variedade de atuação: alguns estados realizam programas com os municípios, em outros há fóruns federativos e, na maior parte, não há coordenação. Para além dessa observação geral, pouco se sabe sobre como os governos estaduais têm atuado nesse jogo federativo.

Este artigo, portanto, analisa a atuação dos governos estaduais no processo de coordenação federativa dos municípios na educação. A literatura recente tem realçado o crescente papel do governo federal nessa política, mas pouco se sabe sobre o modo como os estados cooperam com os municípios. Empiricamente, a pesquisa analisou essa cooperação em seis estados: Acre, Ceará, Mato Grosso do Sul, Minas Gerais, Pará e São Paulo. A escolha não se deveu somente a diferenças regionais, como ainda considerou os legados e escolhas nessa política.

$\mathrm{O}$ artigo mostra que há três pontos essenciais que devem ser considerados. Primeiro, as ações do governo federal nos municípios são, em alguns casos, mediadas pelos estados. Em segundo lugar, os governos estaduais podem adotar medidas de articulação com os governos locais e o fazem, seja em razão e por meio da sua rede de ensino - algo que o governo federal não tem -, seja por meio de políticas educacionais de indução ou transferência de recursos. Em alguns casos, a cooperação é caracterizada por pouca negociação e realizada de maneira vertical, enquanto em outros ocorre o inverso.

Em terceiro lugar, os achados empíricos realçam que as diferenças interestaduais em termos socioeconômicos, institucionais e de escolhas de políticas conformam modelos diversos de coordenação federativa, afetando até mesmo a forma 
como o governo federal atua na educação. Mais que uma dicotomia centralização/ descentralização, encontrou-se um jogo caleidoscópico de relações intergovernamentais.

Para isso, o presente artigo está divido em três partes. Na primeira, há uma breve apresentação da produção bibliográfica sobre federalismo e relações intergovernamentais. Na segunda, é apresentada a constituição da trajetória da política educacional no Brasil no que se refere às relações intergovernamentais. E a terceira compreende a pesquisa empírica, ou seja, a descrição e análise dos seis estados.

\section{BREVE EXPLICAÇÃO TEÓRICA SOBRE FEDERALISMO E RELAÇÕES INTERGOVERNAMENTAIS}

A definição mais clássica de federalismo aponta que, em federações, diferentes governos regulam um mesmo território, mas cada um deles tem exclusiva competência sobre determinadas matérias (Riker, 1975). Elazar (1991) afirma que o federalismo compreende a necessidade de se alcançar propósitos comuns e proteger certos direitos para a manutenção da integridade das partes. Ele enfatiza, dessa forma, que o federalismo compreende uma combinação especial entre autonomia e interdependência entre os níveis de governo. Observando a origem etimológica da palavra federação, trata-se, na verdade, de um pacto, no qual os entes federados são participantes.

Nesse sentido, as relações entre as partes constitutivas da federação, chamadas de relações intergovernamentais, referem-se a uma forma particular de Estado que envolve extensiva e contínua relação entre o governo federal e os governos subnacionais. Essa ligação supõe negociação e barganha na formulação e implementação de políticas públicas. As relações intergovernamentais são, portanto, o modo como se concretiza a cooperação em países federativos.

Outra característica do federalismo refere-se à existência de descentralização de competências entre o governo federal e os governos subnacionais. No entanto, vários autores alertam que descentralização não é sinônimo de federalismo, pois há processos descentralizadores também em sistemas unitários e há federações que apresentam graus variados de descentralização e, consequentemente, de centralização (Mueller, 2012).

O federalismo, portanto, modifica a autoridade e o modo como as políticas são formuladas, implementadas e, por fim, os seus resultados. Assim como Elazar (1991), Wright (1988) destaca a importância das interações entre os níveis de governo nas políticas públicas. Para ele, elas são resultado dessas interações formais ou informais entre os atores presentes nas distintas unidades de governo. Ou seja, a presença de barganha e negociação entre esses atores leva a uma maior cooperação entre eles.

Outros autores avançam no significado empírico do que seriam as formas de relações intergovernamentais. Com base em uma pesquisa sobre vinte e cinco países federativos, Agranoff (2007) formula quatro categorias de relações entre os entes federados, que são: econômica (subsídios, transferências e empréstimos intergovernamentais, comissões fiscais, aquisição de bens e serviços e contratação 
de pessoal de outros governos), legal (regulação e acordos de operação conjunta de um programa), administrativa (contratos para serviços e programas entre governos, cessão de pessoal, auditorias, autoridades especiais, governos metropolitanos ou regionais e desempenho negociado de programas) e política (redes, conselhos e conferências intergovernamentais, lobbying e representação intergovernamental).

Banting (2005) e Watts (2006) também mostram que há diferentes modos de relações intergovernamentais coexistindo em um único sistema federativo. Há formas mais verticais e unilaterais, em que um dos entes age de maneira independente: horizontais e cooperativas, em casos em que há acordos, programas conjuntos com compartilhamento de custos e negociações para resolução de determinados problemas; e intermediárias, nas quais o governo federal, por exemplo, dá suporte financeiro para a implementação de determinado programa ou troca de informações entre os entes. É importante ressaltar que essas formas variam no grau de institucionalização, ou seja, podem ser informais ou formais.

Destaca-se que, nas federações com maiores disparidades socioeconômicas e de capacidades estatais dos níveis de governo, em geral o governo federal busca reduzir desigualdades entre as regiões e os governos subnacionais por meio da redistribuição de recursos e da indução de políticas e melhorias nas gestões locais. Nesse caso, a literatura apresenta mais explicitamente o conceito de coordenação federal (Obinger; Leibfried; Castles, 2005).

Os estudos que analisam as relações entre estados e governos locais em países federalistas mostram, em primeiro lugar, que há uma variação dos desenhos institucionais e territoriais entre os governos locais e, em segundo lugar, que há uma heterogeneidade de tipos de relações entre eles.

Nos Estados Unidos (EUA), a discricionariedade dos governos locais ${ }^{1}$ depende da descentralização de ações, das transferências de recursos e da ação direta dos estados. Lá podem ser encontrados órgãos regionais, conselhos, convênios, câmaras no legislativo estadual para tratar de determinados assuntos locais ou de determinadas municipalidades e câmaras autônomas, nas quais as municipalidades discutem problemas sem a interferência estadual (Zimmerman, 1995; Wilson; Gamkhar, 2011).

$\mathrm{Na}$ Alemanha, há governos locais e governos regionais. ${ }^{2}$ Os governos locais têm competências delegadas (segurança pública, proteção da natureza, fiscalização, registro, eleitorais etc.), próprias e facultativas (cultura, esporte, transporte, idoso, juventude etc.) e obrigatórias (segurança, abastecimento de água e tratamento de esgoto, transporte coletivo, construção de vias públicas, manutenção de prédios escolares e hospitais etc.). Essas competências são supervisionadas pelos estados e os governos locais podem estabelecer relações cooperativas para a resolução de

1 Nos EUA, há uma grande heterogeneidade de governos locais, que chegam a mais de oitenta mil entre condados, municípios, pequenas cidades, distritos escolares e distritos especiais (Wilson; Gamkhar, 2011).

2 Tratando-se de cooperação intermunicipal, há cerca de trezentos Kreise, com vinte a trinta municípios cada (Krell, 2003), e Landkreis, que são esferas político-administrativas regionais com poderes Legislativo e Executivo (Carneiro; Dill, 2011). 
problemas que envolvem mais de um município ou assumem funções municipais, até mesmo, em alguns casos, a cooperação envolve subsídios financeiros para aumento da capacidade institucional dos governos locais (Carneiro; Dill, 2011; Krell, 2003).

No Canadá, as atribuições dos governos locais ${ }^{3}$ variam segundo a descentralização feita pelas províncias que controlam esses governos por meio de recursos destinados a eles e de regulamentação (Sancton, 2010).

De maneira sintética, a literatura mostra que há um continuum de cooperação mesmo com a multiplicidade de governos locais e suas diferentes atribuições entre os países. Em um extremo, há práticas mais institucionalizadas e com maior entrelaçamento entre os entes e, no outro, ações mais informais e com menor entrelaçamento. É importante ressaltar que podem ser encontradas, em um mesmo país, práticas mais e menos institucionalizadas e mais e menos entrelaçadas, dependendo da política pública.

\section{MÉTODOS DE PESQUISA}

Como apresentado na introdução, a pesquisa analisou as relações entre estados e municípios na política educacional em seis estados: Acre, Ceará, Mato Grosso do Sul, Minas Gerais, Pará e São Paulo. A seleção dessas experiências teve como base o fato de que a Federação brasileira é bastante heterogênea, levando em conta, então, as diferentes capacidades institucionais, econômicas e sociais dos estados. Com base nessa heterogeneidade, foram estudados dois estados que possuem uma cooperação mais desenvolvida, Ceará e Mato Grosso do Sul, dois estados que possuem uma cooperação mais fraca, Pará e São Paulo, e dois estados intermediários na cooperação, Acre e Minas Gerais.

A análise dos seis casos estudados foi feita com base em análise documental e em entrevistas semiestruturadas com atores-chave - tanto ligados aos casos estudados como também ao governo federal e municípios, especialmente as seccionais da União Nacional dos Dirigentes Municipais de Educação (UNDIME). Os estados foram visitados entre setembro de 2012 e fevereiro de 2013, em um trabalho de campo com entrevistas e observação in loco. Os resultados obtidos foram analisados qualitativamente por meio da criação de uma categorização que procurou classificar os casos em um continuum de maior ou menor cooperação.

\section{A FEDERAÇÃO BRASILEIRA E AS RELAÇÕES INTERGOVERNAMENTAIS NA EDUCAÇÃO}

O retorno à democracia trouxe a proposta de reforço da autonomia dos governos subnacionais e da descentralização das políticas públicas. De fato, a Federação brasileira é hoje mais equilibrada no que se refere à divisão dos poderes e recursos entre os níveis de governo em comparação ao regime militar e mesmo em relação ao

3 No Canadá, os governos locais compreendem cidades, municípios, vilas, condados, cento e cinquenta e cinco municipalidades e vinte e sete distritos regionais (Sancton, 2010). 
período de 1946-1964. No entanto, o desequilíbrio de épocas anteriores não gerou um governo federal fraco nem desnecessário. Ao contrário, a Constituição de 1988 ressaltou a importância da União no que diz respeito a competências materiais e, sobretudo, legislativas, além de ter-lhe conferido um papel de coordenação federal muito importante no combate às desigualdades territoriais e na suplementação ou indução de ações no plano subnacional.

Esse papel do governo federal tornou-se mais importante com a transformação dos municípios em entes federativos. Por mais paradoxal que possa parecer, a maior autonomia local num país bastante desigual exige maior apoio e atuação intergovernamental dos outros dois níveis de governo. Segundo Abrucio, Franzese e Sano (2010, p. 185), a descentralização municipalista promovida pela Constituição Federal de 1988,

em um país em que a desigualdade entre os municípios é maior do que a desigualdade entre as cinco regiões, gerou nova heterogeneidade constitutiva da Federação brasileira. Às heterogeneidades vinculadas à dimensão física, às diferenças socioculturais e políticas das sociedades e elites subnacionais e às assimetrias socioeconômicas entre as regiões deve-se acrescentar a disparidade de situações entre os municípios, os quais são agora entes federativos plenos, formalmente homogêneos e responsáveis por várias ações governamentais. Trata-se, então, de uma questão que requer remédios federativos para ser equacionada, mais especificamente a adoção de instrumentos de coordenação e cooperação intergovernamental.

$\mathrm{Na}$ educação, a desigualdade entre as jurisdições é um elemento presente em toda a trajetória da política. Antes da Constituição Federal de 1988 não havia uma forte coordenação ou orientação do governo federal. Cabe frisar, inicialmente, que até a promulgação da Constituição Federal de 1988 a educação básica era responsabilidade principalmente dos estados e dos municípios e, salvo ações pontuais nas regiões mais pobres e em políticas específicas (como o Movimento Brasileiro de Alfabetização - MOBRAL), o governo federal atuou pouco para reduzir as desigualdades educacionais no país. Permaneceu ao longo da história, desde a Lei Geral de 1827, um modelo dualista, no qual o governo central (depois federal) ateve-se mais ao ensino superior, ao passo que aos governos subnacionais coube, basicamente, os níveis educacionais do primário, ginasial e secundário (Abrucio, 2010).

Dessa divisão surgiu também, como notou Cury (2007), uma duplicidade de redes. Essa estrutura em si não é problemática, pois muitos países federativos funcionam desse modo. O problema é que à duplicidade somou-se, ao longo da história, uma falta de articulação e coordenação entre as redes de ensino num ambiente de grande desigualdade no plano subnacional, sobretudo em virtude das diferenças financeiras e institucionais nas regiões brasileiras (Oliveira; Souza, 2010).

A duplicidade de redes, ademais, teve como base uma divisão perversa de responsabilidades. O governo central era, disparado, o mais forte ao longo do Império e, a partir da Revolução de 1930, foi a União o ente que mais se fortaleceu do ponto de vista institucional e financeiro. Nesse cenário, coube primordialmente 
a ele o encargo com o ensino superior, com uma atuação mais subsidiária para os outros ciclos educacionais, que se tornou crescente no regime militar com o ensino técnico do então segundo grau.

Enquanto isso, os governos subnacionais ficaram com a incumbência de cuidar dos primeiro níveis educacionais - o que é chamado hoje de educação básica. $\mathrm{O}$ problema é que o poder local foi bastante frágil no período monárquico e, embora os estados tenham adquirido enorme poder político na Primeira República, havia uma enorme heterogeneidade entre eles. Nesse sentido, somente uma pequena parcela deles conseguiu construir um sistema educacional de melhor qualidade. Do primeiro Governo Vargas até o final do regime militar, não houve uma grande evolução dos governos estaduais no campo das políticas públicas - e, quando ocorreu, foi geralmente em um pequeno conjunto de estados mais desenvolvidos -, além dos municípios terem sido o polo frágil do federalismo.

Em suma, do ponto de vista federativo, a duplicidade de redes e responsabilidades facilitou a construção de um modelo pernicioso no qual as ações mais importantes favoreceram o ensino superior, ao passo que a educação básica teve um espaço mais difícil para se desenvolver. $O$ resultado dessa divisão foi a instituição de uma estrutura elitista de provisão do serviço educacional.

O capítulo da educação na Constituição de 1988 procurou reagir a esse legado federativo. Ele seguiu, em boa medida, os cinco parâmetros que nortearam a normatização e ampliação do Welfare State por meio do novo texto constitucional (Abrucio, 2010). O primeiro aspecto foi a busca da universalização dos direitos sociais, ponto bastante presente na área educacional, que expressou esse valor na letra da lei - obrigatoriedade do ensino dos 7 aos 14 anos - e aumentou as fontes de financiamento com o intuito de ampliar a cobertura escolar, pelo menos do ensino fundamental. $\mathrm{O}$ artigo 212 definiu que caberia à União aplicar percentual mínimo de $18 \%$ em educação, ao passo que estados e municípios teriam de gastar ao menos $25 \%$ de suas receitas.

O segundo parâmetro foi a democratização da gestão estatal, visando aumentar a participação dos atores educacionais no processo decisório, seguindo, em grandes linhas, o que fora proposto em outras áreas sociais, mormente na ideia de Conselhos de Políticas Públicas. Outra referência constitucional foi o ideal de profissionalização da burocracia, que teve como prioridade realizar concursos públicos e construir carreiras nas principais atividades do Estado como provedor de serviços públicos.

Além desses, dois outros parâmetros modificaram de maneira mais intensa o modelo educacional e o tornaram mais complexo. Um deles foi a descentralização, que na educação (como em outras áreas) centrou o foco na municipalização, sem, no entanto, proibir a existência das redes estaduais, que continham o maior número de alunos e eram hegemônicas em muitos estados. Outro parâmetro foi a preocupação de levar em conta a questão das relações intergovernamentais, até porque havia um temor entre os atores educacionais de que uma descentralização profunda poderia levar ao aumento da desigualdade (Araujo, 2005).

O resultado constitucional na área de educação pode ser considerado bem equilibrado do ponto de vista federativo (Abrucio, 2010). O artigo 211 da Constituição resume esse modelo ao propor três situações. A primeira foi a divisão de 
competências mais descentralizadas da execução dos serviços, dando um peso importante aos municípios. Em segundo lugar, foram adotados instrumentos para evitar uma descentralização centrífuga, que seria indesejável para um país tão desigual como o Brasil. Nesse sentido, foram colocados dois pontos: a noção de competência comum, segundo a qual um nível de governo atua prioritariamente sobre um ciclo, mas outro também poderá fazê-lo, evitando, em tese, o vácuo no acesso aos bens públicos, além de a União ter obtido grande capacidade para produzir diretrizes e normas nacionais, ao que se soma a sua função redistributiva e supletiva, "de forma a garantir a equalização das oportunidades educacionais e padrão mínimo de qualidade de ensino mediante assistência técnica e financeira aos Estados, ao Distrito Federal e aos Municípios" (Brasil, 1988, artigo 211).

A lógica do artigo 211 completa-se com a noção de regime de colaboração, cujo objetivo seria a articulação dos entes federativos nas várias ações educacionais que lhes cabem. Dada a existência de redes duais, particularmente no ensino fundamental, de competências comuns e de ações supletivas da União, seria necessária a cooperação entre os níveis de governo para evitar choques ou ações descoordenadas capazes de provocar uma piora na qualidade da política. Desenha-se, aqui, o federalismo cooperativo proposto para a área educacional, que foi reforçado depois por um parâmetro nacional, a Lei de Diretrizes e Bases da Educação Nacional (LDB), aprovada em 1996.

Na educação, a Constituição Federal de 1988, portanto, promoveu tanto a coordenação do governo federal na assistência financeira e técnica a estados e municípios quanto a cooperação entre os três entes. Essa cooperação foi traduzida, no texto constitucional, por uma expressão: regime de colaboração. Neste artigo, optamos, portanto, pela utilização do conceito de cooperação, destacando que, na política educacional, ele está vinculado à noção de regime de colaboração.

Aos avanços constitucionais na área educacional somaram-se às experiências inovadoras ocorridas em vários governos locais. Porém, o fato é que permaneceram questões federativas mal resolvidas no pós-1988. A descentralização foi inicialmente muito díspar no seu processo de implementação, aumentando a desigualdade de acesso e não garantindo o grande objetivo, que era a universalização do ensino por meio do aumento da cobertura escolar.

A partir de 1995, o governo federal adotou medidas para tentar melhorar a coordenação federativa (Abrucio, 2005). Essa iniciativa foi resultado de uma variedade de fatores, entre eles a crise fiscal dos estados brasileiros e a necessidade de coordenar o repasse de funções aos municípios.

A política educacional corrobora a ideia de que o governo federal passou a ter um papel de coordenador na Federação brasileira a partir dessa data. Houve mudanças na redistribuição de recursos com o Fundo de Manutenção e Desenvolvimento do Ensino Fundamental e de Valorização do Magistério (FUNDEF); nas transferências federais, que antes eram realizadas de maneira clientelista e passaram a ser baseadas em determinados critérios, e alguns programas, que então passaram a descentralizar os recursos às escolas; na regulamentação federal e na formulação de diretrizes nacionais, com a LDB e o Plano Nacional de Educação (PNE); nos sistemas de avaliação e informação, por meio do Sistema de Avaliação 
da Educação Básica (SAEB) e do Censo Escolar, que eram importantes para o controle das transferências do FUNDEF; e na criação de espaços participativos, como o Conselho Nacional de Educação (CNE). No caso do FUNDEF, os resultados mais importantes foram o aumento das matrículas no ensino fundamental, a municipalização dessa etapa de ensino e a diminuição das desigualdades de gasto intraestaduais (entre a rede estadual e a rede municipal de cada estado).

O governo federal aprofundou sua atuação na coordenação federativa durante o Governo Lula, conforme afirmam Abrucio, Franzese e Sano (2010). Na educação, essa participação ocorreu por meio de vários programas e ações que buscaram redistribuir recursos ou aumentar a articulação entre os níveis de governo mediante uma norma federal. Nessa linha, podem ser citados como casos de coordenação federal a criação do Plano de Ações Articuladas (PAR), do Plano de Metas Compromisso Todos pela Educação, da Prova Brasil, da Provinha Brasil e do Índice de Desenvolvimento da Educação Básica (IDEB) e do Fundo de Manutenção e Desenvolvimento da Educação Básica e de Valorização dos Profissionais da Educação (FUNDEB).

Nessa mesma linha, o Governo Dilma criou a Secretaria de Articulação com os Sistemas de Ensino (SASE) com o objetivo de ter um sistema nacional. A importância dessa articulação intergovernamental se dá, principalmente, em dois aspectos. O primeiro é que, como já apresentado, a existência de uma duplicidade de redes - estadual e municipal - ainda gera competição e, particularmente, descoordenação entre os níveis de governo. O segundo é que ainda há um bom contingente de estados com uma enorme rede de ensino, convivendo com outros estados em que a municipalização avançou bastante. Essa heterogeneidade de redes não encontra paralelo em outras políticas sociais.

\section{O REGIME DE COLABORAÇÃO NA EDUCAÇÃO EM SEIS ESTADOS BRASILEIROS}

A descrição e análise dos casos selecionados serão apresentadas nesta seção de maneira comparada. Em primeiro lugar, serão apresentados o modo como a cooperação entrou na agenda e a sua trajetória nos estados, em segundo, o seu conteúdo (programas e ações) e, em terceiro, seus dilemas e avanços. Como indicado, a metodologia incluiu a análise qualitativa de documentos e entrevistas qualitativas com gestores das secretarias estaduais e municipais de educação e do Ministério da Educação (MEC) e os atores da sociedade civil organizada.

\section{A TRAJETÓRIA DA COOPERAÇÃO ENTRE OS ESTADOS E OS MUNICÍPIOS NA EDUCAÇÃO}

Em alguns dos estados analisados, há uma trajetória mais longa de entrelaçamento e institucionalização entre o Estado e os municípios. No entanto, como será mostrado, maior entrelaçamento não significa maior institucionalização. Além disso, nas experiências em que há maior cooperação, os secretários estaduais e sua equipe, que fortaleceram a cooperação, tiveram experiências anteriores como se- 
cretários municipais e, assim, influenciaram a introdução do assunto na agenda ou o seu fortalecimento.

No Ceará, desde a década de 1970, há programas de municipalização do ensino fundamental. Naquele momento, foi adotado o Programa Pró-Município do MEC, em que a Secretaria da Educação do Estado do Ceará dava assistência técnica e financeira aos municípios que se responsabilizavam pelo ensino fundamental. Outros programas de municipalização foram implementados no governo de Tasso Jereissati (1995-2002), no qual havia indução financeira para a municipalização, e no governo de Lúcio Alcântara (2003-2005) (Viera,2010). Esses incentivos resultaram na municipalização de quase a totalidade do ensino fundamental.

Apesar dessa divisão entre as redes estadual e municipais de ensino, em 2007 foi criado o Programa Alfabetização na Idade Certa (PAIC). Os entrevistados relataram que tal projeto fora resultado de uma pesquisa e de um programa-piloto realizados em 2004 pelo Comitê Cearense para a Eliminação do Analfabetismo Escolar, que contava com o apoio da Assembleia Legislativa, do Fundo das Nações Unidas para a Infância (UNICEF), da Associação dos Municípios do Estado do Ceará (APRECE), da UNDIME do Ceará, da Secretaria da Educação do Estado do Ceará e do Instituto Nacional de Estudos e Pesquisas Educacionais Anísio Teixeira (INEP). Além desses, a Universidade Estadual do Ceará (UECE), a Universidade Federal do Ceará (UFC), a Universidade Estadual Vale do Acaraú (UVA), a Universidade de Fortaleza e a Universidade Regional do Cariri (URCA) também eram parceiras.

A criação desse comitê foi resultado de uma pesquisa realizada por Ivo Gomes quando era deputado estadual. A pesquisa contava com três partes: avaliação amostral dos níveis de leitura, escrita e compreensão de texto com cerca de oito mil alunos da segunda série do ensino fundamental, análise dos programas dos cursos de pedagogia de cinco instituições e do uso do tempo escolar e da organização do trabalho escolar e docente na alfabetização. A pesquisa mostrou deficiências nos três pontos, mas especialmente na avaliação dos alunos os resultados foram preocupantes. Em decorrência desses resultados, o comitê elaborou o PAIC e o colocou em prática em cinquenta e seis municípios.

Nesse período, Cid Gomes era prefeito do município de Sobral e implementou durante sua gestão um programa de alfabetização. Quando ele assumiu o governo estadual, a Secretaria da Educação adotou o PAIC em todo o estado. No início da implementação do programa, todos os municípios aderiram com a assinatura de um termo de adesão, que é renovado com a mudança dos prefeitos municipais. Atualmente, o PAIC inspirou um programa nacional elaborado pelo MEC, o Pacto Nacional pela Alfabetização na Idade Certa (PNAIC).

No Mato Grosso do Sul, foi criada uma coordenadoria de apoio aos municípios em 2007 na gestão da então secretária estadual, Nilene Badeca, que foi secretária municipal de Campo Grande de 1997 a 2000 e de 2001 a 2004. No início do fortalecimento da cooperação no estado, as reuniões entre a secretaria estadual e as secretarias municipais eram realizadas com intermediação da seccional da UNDIME no estado, mas atualmente a secretaria estadual estabeleceu um vínculo direto com as secretarias municipais. 
Ao contrário do caso anterior, não houve um processo linear de municipalização no Mato Grosso do Sul. Segundo relatado nas entrevistas, a meta da secretaria estadual é municipalizar o primeiro ciclo do ensino fundamental, e, caso o município não tenha capacidade institucional e financeira para essa mudança, o estado reassume as séries.

A cooperação nesse caso se fortaleceu mais na assessoria técnica aos municípios. Ela é realizada pela secretaria estadual às secretarias municipais de educação e é um pré-requisito para a adoção de alguns programas federais. Na maioria dos estados, no entanto, ela não foi institucionalizada como uma atividade da secretaria estadual, e assim não é feita por um órgão específico. Caso algum município tenha possíveis dúvidas, ele recorre ao burocrata responsável. Em razão disso, esse tipo de cooperação tem sido mais adotado pelas secretarias estaduais. Entre os casos analisados, o Ceará e o Mato Grosso do Sul possuem essa forma de cooperação. Apesar disso, no segundo, o estado ocupou formalmente o papel de assessoria e acompanhamento do PAR e dos programas federais por uma negociação feita pela secretária Nilene Badeca com o MEC.

Mais próximo do caso do Mato Grosso do Sul, no Acre não havia uma trajetória de ações conjuntas entre o governo estadual e os governos municipais. A partir dos últimos anos, com a eleição da Frente Popular do Acre no governo estadual e na prefeitura municipal de Rio Branco, a cooperação entre estado e municípios foi iniciada. Segundo o então secretário municipal de educação de Rio Branco e presidente da UNDIME-AC, Marcio Batista, esse processo começou em 2005, quando houve uma articulação entre o então governador do estado, Jorge Viana, o secretário estadual de Educação, Binho Marques, e o prefeito do município de Rio Branco, Raimundo Angelim.

Essa articulação gerou uma avaliação dos alunos e professores das redes estadual e municipal. Verificou-se que muitos professores não tinham nível superior - o diretor de ensino da Secretaria de Estado de Educação e Esporte afirmou que havia, em 1999, somente 23\% de professores com nível superior. Em virtude dessa realidade, foi implementado um programa de formação inicial de professores em parceria com a Universidade Federal do Acre (UFAC).

Assim como no caso do Acre, em Minas Gerais não há um órgão específico responsável pela articulação entre o estado e os municípios. A trajetória da cooperação é recente, pouco institucionalizada e fragmentada. Apesar disso, a municipalização ocorreu a partir da década de 1990. A cooperação é estabelecida por meio de uma série de programas conjuntos, que são implementados pelos diferentes órgãos da secretaria estadual e que muitas vezes já eram implementados na rede estadual de ensino. Esse é o caso do Programa de Intervenção Pedagógica (PIP), colocado em prática desde 2006 na rede estadual de ensino.

Em São Paulo, assim como no Ceará, houve programas de municipalização ao longo das últimas duas décadas. Especialmente a partir da gestão de Rose Neubauer (1995-2002), foi realizado um grande esforço para a municipalização do ensino fundamental. Apesar do empenho, a rede estadual ainda tem um grande volume de matrículas no ensino fundamental. O histórico de cooperação entre o estado e os municípios concentrou-se na adesão dos municípios de alguns dos programas realizados na rede estadual, o que será aprofundado na próxima seção. 
Em um continuum de cooperação, a experiência de São Paulo está mais próxima ao caso do Pará, embora nesse haja menos cooperação que no caso de São Paulo. No Pará, a municipalização foi bem-sucedida, a maior parte das matrículas é ofertada pelos municípios. No entanto, a continuidade desse processo foi enfraquecida pelos resultados dos programas anteriores. Os municípios, por exemplo, não conseguem alcançar o salário pago aos professores da rede estadual, o que gera uma competição entre as redes de ensino.

Fica evidente que há uma grande diferença entre as trajetórias de cooperação nos estados analisados. Verifica-se que, em alguns deles, a relação entre o estado e os municípios foi iniciada por programas de municipalização e, em outros, por uma mudança política, isto é, da entrada de atores municipais na esfera estadual. Ademais, a entrada da cooperação na agenda dos governos estaduais se deu após a Constituição Federal de 1988 ou mais recentemente. Com exceção dessa medida nacional, cada estado tem uma trajetória distinta que envolve a resolução de problemas diferentes.

\section{HÁ COOPERAÇÃO ENTRE OS ESTADOS E OS MUNICÍPIOS NA EDUCAÇÃO?}

Assim como a trajetória de cooperação entre os estados e os municípios, o conteúdo da política varia bastante entre os casos analisados. No caso do Ceará, o governo realiza ações em diversas frentes e interfere mais fortemente nos sistemas municipais de ensino, especialmente com o PAIC, incluindo indução financeira. No Mato Grosso do Sul, há a implementação de um programa estadual de alfabetização nas redes municipais e assessoria técnica. No Acre, há formações conjuntas e um programa de alfabetização para comunidades de difícil acesso. Em Minas Gerais, há um programa de assessoramento pedagógico. Em São Paulo, os programas estaduais são abertos para a participação dos municípios, porém sem ações motivadoras, e, no Pará, não há ações conjuntas significativas. É importante apontar que, na maior parte dos estados, as avaliações estaduais são realizadas nas redes municipais, há convênios de transporte e merenda escolar e cessão de prédios e recursos humanos na reordenação das redes.

Como apontado, a política de cooperação entre a Secretaria da Educação do Estado do Ceará e os municípios cearenses é responsabilidade da Coordenadoria de Cooperação com os Municípios. O maior destaque da cooperação é o PAIC, que enfoca a alfabetização apresentando como suas principais ações: a formação da burocracia das secretarias municipais e das escolas, a distribuição de materiais didáticos e a realização de avaliações. Houve também a criação de equipes nas secretarias municipais responsáveis pelo PAIC, que se comunicam com a Coordenadoria Regional de Desenvolvimento da Educação (CREDE). Vale destacar que a secretaria estadual premia as escolas que apresentam maior desempenho, no entanto a escola só recebe o recurso total se conseguir melhorar o desempenho de uma escola com menor desempenho valendo-se de sua assessoria.

Além da premiação, há outros mecanismos de indução. No Programa de Transporte Escolar, o governo estadual repassa o recurso ao município para a prestação do serviço de transporte promovendo ainda a doação de veículos. O governo estadual também financia a construção dos Centros de Educação Infantil (CEI). 
Outro incentivo financeiro é o Imposto sobre Circulação de Mercadorias e Serviços (ICMS) da educação. O governo estadual estabeleceu que a cota-parte do imposto (25\%) é repassada segundo os índices de qualidade de saúde, meio ambiente e educação. O índice de qualidade de educação representa $18 \%$ e é formado pela taxa de aprovação dos alunos do primeiro ao quinto ano do ensino fundamental e pela média municipal de proficiência obtida pelos alunos do segundo ano e quinto ano.

No Mato Grosso do Sul, o foco da cooperação está na assessoria técnica aos municípios para a elaboração do PAR, já que é a secretaria estadual a responsável pelo acompanhamento do plano nos municípios (em vez das universidades federais, o que ocorre em outros estados), e na implementação do programa de alfabetização denominado Além das Palavras, que compreende formações e distribuição de materiais pedagógicos. A secretaria ainda realiza formações continuadas para professores e para gestores das secretarias municipais, oferta de cursos técnicos e profissionalizantes em parceria com os municípios, distribuição de ônibus para as prefeituras realizarem o transporte escolar, cessão e permuta de equipamentos, prédios e profissionais e elaboração de calendários comuns.

Nesse tipo de cooperação, o estado intermedeia a relação entre o governo federal e os municípios. A secretaria estadual, no início desse processo, fez visitas às secretarias municipais com a finalidade de reformular os PARs municipais para demandas e necessidades reais das redes municipais de ensino. Atualmente, ela também assessora as secretarias municipais à adesão, acompanhamento e prestação de contas dos programas federais.

O caso do Acre não inclui ações tão abrangentes e indutivas como nos casos anteriores. No início, a cooperação começou com a formação inicial de professores, o governo estadual pagava os professores bolsistas da UFAC e os municípios garantiam a logística e a infraestrutura. Além dessa medida, acordaram uma ampliação das vagas dos cursos superiores da universidade. Em seguida, implementaram a formação continuada para os professores, que funciona da seguinte forma: se o governo estadual oferece formação, os municípios são convidados a participar, e, se os municípios oferecem formação, o estado é convidado. Essa última modalidade é menos frequente que a primeira.

Outro componente da cooperação é o reordenamento das redes municipais e estaduais de ensino. Para o atual secretário estadual de Educação, um dos benefícios trazidos pelo FUNDEB foi a concorrência por matrículas entre as redes. Com isso, havia, no Acre, municípios com escolas de diversas etapas do ensino e séries, levando a uma falta de identidade pedagógica das escolas e problemas de infraestrutura. Para resolver esse problema, houve uma redefinição das competências dos entes, ou seja, foram determinadas quais séries seriam responsabilidades exclusivas do município e quais seriam do estado. Essa separação permitiu a prática da matrícula cidadã, em que os alunos saem de uma escola e já têm a vaga assegurada na outra escola da região.

Há a implementação da avaliação externa nas redes estadual e municipal de ensino. Atrelado a ela, foi estabelecido entre estado e municípios o Pacto pela Educação, que se refere à discussão de metas para a melhoria da qualidade da educação no estado. As negociações e pactuações entre estado e municípios são 
realizadas nas reuniões da UNDIME-AC. Por último, é realizado um programa estadual de alfabetização nas comunidades de difícil acesso em parceria com os municípios, o Asas da Florestania Infantil, parte do ProAcre. ${ }^{4}$

Em Minas Gerais, as formas de cooperação incluem a participação dos municípios no Sistema Mineiro de Avaliação da Educação Pública (SIMAVE) e do PIP. O SIMAVE compreende uma avaliação interna da escola, o Programa de Avaliação da Aprendizagem Escolar (PAAE) e uma avaliação externa, o Programa de Avaliação da Alfabetização (PROALFA) e o Programa de Avaliação da Rede Pública de Educação Básica (PROEB). O PIP visa melhorar o desempenho dos alunos por meio de intervenções pedagógicas nas escolas feitas por uma equipe da secretaria estadual com base em seus resultados nas avaliações. A secretaria estadual auxilia os municípios na estruturação e capacitação das equipes do PIP municipal e oferece material de apoio.

A secretaria estadual também cede e permuta mobiliários, equipamentos e profissionais às redes municipais, realiza a manutenção e a renovação da frota de veículos e dá orientação aos municípios na elaboração e execução do PAR.

A cooperação existente no estado de São Paulo compreende a adesão dos municípios aos programas estaduais. Entre eles estão: o Programa de Ação de Parceria Educacional Estado-Município para Atendimento do Ensino Fundamental, que visa ampliar o atendimento de crianças na educação infantil, mediante a transferência de recursos financeiros para construção, ampliação, reforma ou adequação de prédios públicos destinados à educação infantil e à aquisição de equipamentos e materiais de natureza permanente; o Programa de Ação Cooperativa Estado-Município para Construções Escolares; São Paulo Faz Escola, no qual o município pode aderir ao currículo oficial do estado de São Paulo; a Rede do Saber, que compreende formação a distância; Ler e Escrever, projeto focado na melhoria das séries iniciais do ensino fundamental por meio de formação e distribuição de materiais pedagógicos; Escola da Família, em que a escola é aberta à comunidade; e avaliação externa. Além desses programas, há a realização da matrícula conjunta.

No Pará, como apontado, não há ações expressivas de cooperação entre a secretaria estadual e as secretarias municipais na educação. Há relação entre os entes na implementação do Sistema de Organização Modular de Ensino (SOME), pois os municípios são responsáveis pelo alojamento, alimentação e transporte dos professores. No entanto, há uma grande insatisfação dos municípios em relação à falta de diálogo com as coordenadorias regionais ligadas à Secretaria de Estado de Educação nesse processo.

Por meio da análise do conteúdo da cooperação nos estados analisados, observa-se que ela ainda é pouco definida e uniforme entre os estados. Em um extremo, há estados mais coordenadores, como o Ceará e o Mato Grosso do Sul, que possuem maior institucionalização e órgãos específicos para essa prática e buscam

4 O ProAcre é um programa financiado pelo governo do estado do Acre e pelo Banco Mundial e visa ampliar o acesso das comunidades de difícil acesso às políticas de educação, saúde e desenvolvimento econômico. 
o aumento da capacidade institucional dos municípios por meio de contratação e formação de pessoal e por assessoria técnica para a elaboração e execução do PAR. Acre e Minas Gerais, apesar de serem estados intermediários na cooperação por haver menos institucionalização, estão mais próximos do Ceará e do Mato Grosso do Sul que de São Paulo e Pará. No outro extremo, encontram-se esses dois últimos estados, em que, em São Paulo, não há debate em torno da cooperação e de projetos que integrem as duas redes, apenas programas estaduais que são abertos para que os municípios participem, e, no Pará, não há nada expressivo.

\section{AVANÇOS E DILEMAS DA COORDENAÇÃO FEDERATIVA}

De maneira esquemática, os seis casos analisados podem ser categorizados em um continuum de cooperação apresentado na Figura 1.

\begin{tabular}{|ccccccc|}
\hline $\begin{array}{c}\text { - Cooperação } \\
\text { - Institucionalização }\end{array}$ & Pará & $\begin{array}{c}\text { São } \\
\text { Paulo }\end{array}$ & $\begin{array}{c}\text { Acre } \\
\text { Minas Gerais }\end{array}$ & $\begin{array}{c}\text { Mato Grosso } \\
\text { do Sul }\end{array}$ & Ceará & $\begin{array}{c}\text { + Cooperação } \\
\text { + Institucionalização }\end{array}$ \\
\hline
\end{tabular}

Figura 1 - Tipos de cooperação entre estados e municípios na Educação

Fonte: Banco de dados da pesquisa.

Elaboração dos autores.

Entre os casos analisados, o Ceará possui uma cooperação mais institucionalizada, na medida em que possui um órgão específico para tratar da relação entre a secretaria estadual e as secretarias municipais. Além disso, possui uma variedade grande de programas que incluem os municípios, sendo o principal o PAIC. É importante ressaltar que esse programa foi construído por um comitê que atuou no plano municipal. Em relação ao conteúdo da cooperação no estado, observa-se que algumas ações visam ao aumento da capacidade institucional dos municípios e inclui indução financeira. Nesse caso, o governo estadual ocupa um papel de coordenador da política educacional, o que pode reduzir as heterogeneidades e desigualdades entre os municípios, característica do federalismo brasileiro.

Assim como no Ceará, no Mato Grosso do Sul há institucionalização da cooperação, que compreende realização de formações, implementação de programas e, especialmente, assessoria técnica para a elaboração e execução do PAR pelos municípios. Essa atividade é de extrema importância para o fortalecimento das secretarias municipais e ocorre também em Minas Gerais.

Apesar de inúmeros programas que estabelecem a cooperação entre estados e municípios, em Minas Gerais e no Acre não há institucionalização. Os programas são baseados em convênios, mas não há um órgão específico que cuide dessa relação. Isso gera uma fragmentação das ações dentro da secretaria estadual fazendo com que cada caso seja tratado separadamente. Nesses estados, são encontrados diferentes estágios de cooperação entre os municípios. Segundo as entrevistas realizadas, o município de Rio Branco (Acre) está em um estágio mais desenvolvido que os 
demais. Houve a reorganização da rede e há formação continuada oferecida pela rede municipal de ensino à rede estadual. Em outros municípios, há somente a permuta de funcionários entre as duas redes de ensino.

Em São Paulo, a cooperação é mais fraca, não há nenhuma negociação e pouca coordenação federativa. Ao contrário dos demais, o governo estadual interfere pouco na política municipal e não influencia fortemente a implementação dos programas federais nos municípios. Porém, há estados que sequer apresentam formas de cooperação entre estado e municípios, como o Pará. Isso não significa que não há relação entre as duas redes, mas que, muitas vezes, ela se baseia na barganha política por meio de distribuição de cargos de confiança às lideranças locais, como os de diretores ou de coordenadores regionais.

A comparação permite verificar que há grande heterogeneidade entre as políticas que compõem a cooperação nos estados brasileiros e pouca institucionalização dos programas implementados e de espaços de negociação entre estado e municípios. Além disso, verifica-se que a cooperação na educação é recente mesmo nos estados em que há a sua maior variedade e institucionalização.

\section{CONSIDERAÇÕES FINAIS}

Considerando a análise dos seis casos, cabe destacar, entre seus resultados, quatro aspectos. Em primeiro lugar, não se pode, no caso da educação, falar em padrão único de atuação dos estados, tanto no que se refere às suas funções como no que tange ao panorama intergovernamental. As diferenças interestaduais - socioeconômicas, institucionais e de escolhas de políticas - modificam as experiências de coordenação federativa.

Em segundo, os estados e municípios realizam concorrentemente a política proposta, até mesmo havendo uma sobreposição de competência no ensino fundamental, o que aumenta a importância da coordenação estadual na prática da cooperação. Isto é, só é possível dar conta dos dilemas da descentralização da educação, especialmente no que se refere às fragilidades nas capacidades institucionais dos municípios, se os estados tiverem um papel coordenador mais bem-sucedido, de modo que não bastam as ações coordenadoras do governo federal.

Em terceiro lugar, é necessário aumentar a articulação entre governo federal e estados para a implementação de políticas educacionais. Isso avançou na parte financeira - com o FUNDEF e o FUNDEB -, mas foi pouco modificado no que se refere à dinâmica política e gerencial da educação. Por exemplo, há poucos programas federais que exigem que os estados os coordenem regionalmente, ainda que, como evidenciado nos casos, alguns estados medeiem as relações federal-local.

Em último lugar, entender que os estados podem desempenhar um papel de coordenação na educação não significa afirmar que esse processo deve ser homogêneo na Federação brasileira. A desigualdade de atuação dos estados deve-se não só a diferenças socioeconômicas, mas a critérios político-institucionais. Como mostrado anteriormente, o estado mais rico da Federação, São Paulo, não tem uma política tão ativa de coordenação, como o Ceará, ou de cooperação, como Mato Grosso do Sul, Acre e Minas Gerais. É provável que o tamanho da rede paulista e sua enorme 
complexidade expliquem parte dessa diferença, mas a trajetória e as escolhas referentes à política não podem ser negligenciadas.

Conclui-se, portanto, que as diferenças entre os estados precisam entrar no arcabouço analítico daqueles que estudam a relação entre federalismo e políticas públicas no Brasil. Em alguns lugares, o governo estadual será mais central, em outros, em menor medida, mas em todos o seu papel é chave para entender o processo de coordenação nos municípios.

\section{REFERÊNCIAS}

Aвrucio, F. L. A coordenação federativa no Brasil: a experiência do período FHC e os desafios do Governo Lula. Revista de Sociologia e Politica, Curitiba: Universidade Federal do Paraná, n. 24, p. 41-67, 2005.

. A dinâmica federativa da educação brasileira: diagnóstico e propostas de aperfeiçoamento. In: Oliveira, R. P.; Santana, W. (Orgs.). Educação e federalismo no Brasil: combater as desigualdades, garantir a diversidade. Brasília, DF: UNESCO, 2010. p. 271-286.

.; Franzese, C.; SAno, H. Coordenação e cooperação no federalismo brasileiro: avanços e desafios. In: Cunha, A. S.; Medeiros, B. A.; Aquino, L. C. (Orgs.). Estado, instituiçôes e democracia: República. Brasília, DF: IPEA, 2010. v. 1, p. 177-212.

AgRANOFF, R. Intergovernmental policy management: cooperative practices in federal systems. In: Pagano, M. A.; Leonardi, R.(Eds.). The dynamics of federalism in national and supranational political systems. New York: Palgrave Macmillan, 2007. p. 248-283.

Araujo, G. C. Município, Federação e educação: história das instituições e das ideias políticas no Brasil. 2005. 333f. Tese (Doutorado em Educação) - Universidade de São Paulo, São Paulo, 2005.

Banting, K. Canada: nation-building in a federal Welfare State. In: Oвinger, H.; Leibfried, S.; Castles, F. (Eds.). Federalism and the Welfare State: new world and European experiences. New York: Cambridge University, 2005. p. 89-137.

Brasil. Constituição da República Federativa do Brasil. Brasília, DF: Senado, 1988.

. Lei n. 9.394, de 20 de dezembro de 1996. Estabelece as diretrizes e bases da educação nacional (LDB). In: SUbChEFIA DE AsSUNTOS JURÍDICOS DA CASA CIVIL DA PRESIDÉNCIA DA REPÚBLICA: LEIS ORDINÁRLAS. Brasília, DF: Casa Civil da Presidência da República do Brasil, 1996.

. Decreto n. 6.094, de 24 de abril de 2007. Dispõe sobre a implementação do Plano de Metas Compromisso Todos pela Educação, pela União Federal, em regime de colaboração com Municípios, Distrito Federal e Estados, e a participação das famílias e da comunidade, mediante programas e ações de assistência técnica e financeira, visando à mobilização social pela melhoria da qualidade da educação básica. In: SUBCHEFLA DE

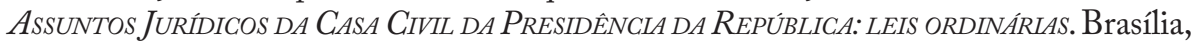
DF: Casa Civil da Presidência da República do Brasil, 2007.

Carneiro, J. M. B.; Dill, G. Arranjos federativos regionais na Alemanha e o papel articulador dos Landkreise. Cadernos Adenauer, Rio de Janeiro: Konrad-Adenauer-Sttifung, n. 4, p. 57-76, 2011. 
Cury, C. R. J. Federalismo político e educacional. In: Ferreira, N. S. C. F. (Org.). Políticas públicas e gestão da educação. Brasília, DF: Líber Livro Editora, 2007. p. 113-129. Elazar, D. Exploring federalism. Tuscaloosa: University of Alabama, 1991.

Krell, A. J. O município no Brasil e na Alemanha: direito e administração pública comparados. São Paulo: Oficina Municipal, 2003.

Mueller, S. Why centralisation? A comparative analysis of the Swiss cantons. 2012. 311f. Tese (Doutorado em Philosophy in Politics \& Government) - University of Kent, Kent, 2012.

Obinger, H.; Leibfried, S.; Castles, F. G. Introduction: federalism and the Welfare State. In:__________ (Eds.). Federalism and the Welfare State: new world and european experiences. New York: Cambridge University, 2005. p. 1-48.

Oliveira, R. P.; Souza, S. Z. Introdução. In: Oliveira, R. P.; Santana, W. (Orgs.). Educação e federalismo no Brasil: combater as desigualdades, garantir a diversidade. Brasilia, DF: UNESCO, 2010. p. 13-35.

Riker, W.H. Federalism. In: Greenstein, F. I.; Polsby, N.W. (Orgs.). Governmental, institutions and processes. Handbook of Political Science, Massachusetts: Addison-Wesley Publishing Company, v. 5, 1975. p. 93-172.

Sancton, A. Local government. In: Courtney, J. C.; Smith, D. E. (Orgs.). The Oxford Hadbook of Canadian politics. Oxford: Oxford University Press, 2010. p. 131-149.

VieIra, S. F.Educação básica no Ceará: construindo um pacto colaborativo. In: Oliveira, R. P.; Santana, W. (Orgs.). Educação e federalismo no Brasil: combater as desigualdades, garantir a diversidade. Brasília, DF: UNESCO, 2010. p. 271-286.

Watts, R. L. Origins of cooperative and competitive federalism. In: GreER, S. L. (Ed.). Territory, democracy and justice: regionalism and federalism in western democracies. New York: Palgrave Macmillan, 2006. p. 201-223.

Wilson, R.; Gamkhar, S. (2011). Cooperação e relações intergovernamentais nos governos locais: o caso dos Estados Unidos. Cadernos Adenauer, Rio de Janeiro: Konrad-Adenauer-Sttifung, n. 4, p. 31-56, 2011.

WRIGHT, D. Understanding intergovernmental relations. Wadsworth: Belmont, 1988.

Zimmerman, J. F. State-local relations: a partnership approach. 2. ed. Westport: Praeger Publishers, 1995.

\section{SOBRE OS AUTORES}

Catarina Ianni Segatto é doutora em administração pública e governo pela Fundação Getúlio Vargas (FGV). É pesquisadora pela mesma instituição. E-mail: catarina.segatto@gmail.com

Fernando Luiz Abrucio é doutor em ciência política pela Universidade de São Paulo (USP). Professor da Fundação Getúlio Vargas (FGV). E-mail: fabrucio@gmail 